\title{
CORRESPONDENCE
}

\section{AGE OF THE WEALDEN IN NORTH-WESTERN EUROPE}

SIR,-I was interested to read (Geol. Mag., xcii, 430-431) Dr. F. W. Anderson's agreement with my main conclusions on the correlation of the English and German Purbeck-Wealden.

His confirmation that Wolburg's correlation of the top Weald Clay of Sussex with the German Wealden 4 zone is incorrect is particularly valuable ; so is his palaeontological explanation of how the mistake came about. My argument (p. 276) was, of course, based mainly on general geological considerations, and it is satisfactory to learn that re-examination of the Berwick ostracods leads to the same conclusion.

Regarding the rest of the succession, Anderson's proposed correlation (unsupported by any new facts) is broadly similar to my own. We appear to differ in the amount of "Wealden 3 " ascribed to Hastings times and in the age of the top of the Hastings Beds. Unfortunately no published work exists on which these and related issues might be settled, and discussion at such a level of precision must remain sterile until it does. That is why my boundaries (Text-fig. 2) are left vague.

Concerning the wider subject of the N.W. European Wealden as a whole, Anderson states (incorrectly, in my view) that "very little of the relevant palaeontology has been published " and that the conclusions " must in many instances remain highly speculative". Large gaps do indeed exist in the ostracod palaeontology of England. But, from what he says next, it is clear that Anderson himself is in a good position to remedy this. A major point of my paper, however, was to restate the old dictum (also disinterred by Hughes (Geol. Mag., xcii, 201)) that all the evidence should be used : molluscs, plants, petrology, as well as the ostracods.

Anderson also raises the fascinating subject of the Cinder Bed. I had already indicated (pp. 269 and 276) that this corresponds approximately with the base of German "Wealden 1 ". It is certainly an important horizon, probably occurring over a great part of the Anglo-Paris basin, and perhaps extending to the Alps.

Since the work under discussion went to press, a new contribution has come to hand which adds further weight to my proposed correlation of Wealden 4 with the Lower Berriasian. Bartenstein and Burri now report (1955, Ecolog. géol. Helv., xlvii, 426) Protocythere propria emslandensis n. subsp. from both of these formations. Incidentally, these are the oldest known occurrences of that genus.

The critical ostracod and other faunas referred to in my paper may be consulted in this Department.

\footnotetext{
Department of Geology,

UNIVERSITY,

READING.

27th October, 1955.
}

P. AlLEN. 